\title{
Sodium valproate-induced enuresis in a pediatric bipolar patient
}

This article was published in the following Dove Press journal:

Neuropsychiatric Disease and Treatment

30 October 2013

Number of times this article has been viewed

\section{Wentao Cheng ${ }^{1, *}$ \\ Xiaoling $\operatorname{Lin}^{2, *}$ \\ Dali Lu'}

'Department of Pediatric and Geriatric Psychiatry, Fuzhou

Neuropsychiatric Hospital, Fuzhou, Fujian, People's Republic of China;

${ }^{2}$ School of Nursing of Central South

University, Changsha, Hunan, People's Republic of China

*These authors contributed equally to this work
Correspondence: Dali Lu

Department of Pediatric and Geriatric Psychiatry, Fuzhou Neuropsychiatric Hospital, Nan Erhuan Road 45I\#, Fuzhou, Fujian, People's Republic of China Tel +86 I85 59| 96659

Email childpsy2012@163.com
Abstract: Sodium valproate (SV) is effective and well tolerated for the treatment of epilepsy and mood disorders. There are several cases of SV-induced enuresis noted in epileptic patients. No alternative medication has been suggested to manage this problem. We present the first case of a pediatric bipolar patient who developed diurnal and nocturnal enuresis during SV therapy. Clinicians should be aware of this side effect, as it has not been reported in nonepileptic patients, and it may be detrimental to treatment adherence.

Keywords: sodium valproate, enuresis, bipolar disorder

\section{Introduction}

Sodium valproate (SV) has a simple chemical structure, and it offers anticonvulsant and mood stabilizing properties. We present the first case, to our knowledge, of a pediatric bipolar patient who developed diurnal and nocturnal enuresis during treatment with SV.

\section{Case report}

"Z," a 14-year-old girl, was referred to our child psychiatry clinic because she was experiencing a mania episode. Both a magnetic resonance imaging scan and an electroencephalography revealed no hint of an organic cause of her manic symptoms. Since her history also revealed a depressive episode, she was diagnosed as having bipolar disorder type 1 using the Kiddie-Sads-Present and Lifetime Version. ${ }^{1}$ Then, the Young Mania Rating Scale ${ }^{2}$ was used to measure the severity of her manic symptoms; her score was 45 .

We started treatment with SV $250 \mathrm{mg} /$ day for the first 4 days. We also administered risperidone $1 \mathrm{mg}$ /day to resolve the ideas of reference symptom throughout the course of treatment. At the 15 th day, the dose of SV was titrated to $750 \mathrm{mg} /$ day $(250 \mathrm{mg}$ at noon and $500 \mathrm{mg}$ at night). Since the SV dose reached $750 \mathrm{mg} /$ day Z began bedwetting. About 4 weeks later, when the dose of SV was titrated up to 500mg twice a day (a blood level of $75 \mu \mathrm{g} / \mathrm{ml}$ ), $\mathrm{Z}$ developed diurnal and nocturnal enuresis every day at the fifth week, she even had urinary incontinence in the classroom at school.

$\mathrm{Z}$ had not taken SV before, and her personal history revealed that she achieved urinary bladder control at 4 years old; since then, she had had no urinary incontinence. The family history was negative for enuresis, and urological and neurological evaluations were normal. Because of the enuresis, the SV dose was reduced to $500 \mathrm{mg}$ /day (a blood level of $38.3 \mu \mathrm{g} / \mathrm{mL}$ ), and her bedwetting disappeared completely 2 days later. 
At her follow-up visit half a year later, she appeared to be well adjusted to the treatment, which consisted of SV at $500 \mathrm{mg} /$ night and risperidone $1 \mathrm{mg} /$ day.

\section{Discussion}

Enuresis is a common problem that can be troubling for children and their families. The causes mostly include functional impairments, such as bladder dysfunction. Previous studies have claimed that risperidone may induce enuresis. ${ }^{3,4}$ However, the girl had taken risperidone $1 \mathrm{mg}$ /day throughout the course of her treatment in our case. Furthermore, enuresis appeared with the increased dosage of SV and disappeared with the decreased dosage of SV. Therefore SV, but not risperidone, was related to bedwetting in the present study.

Our literature search identified 14 case reports that described the induction of enuresis in children with epilepsy who were treated with SV, but there was an absence of literature examining nonepileptic patients. ${ }^{4-9}$ Moreover, none of the patients presented with diurnal enuresis. In line with these case reports, Z's symptoms disappeared after dose reduction, indicating a dose-related side effect. ${ }^{5-9}$ An explanation for the exacerbation of enuresis during SV treatment remains speculative.

According to Choonara, ${ }^{7}$ two of the most likely explanations include that enuresis is a consequence of increased depth of sleep, ${ }^{7,8}$ or that enuresis is secondary to a central effect that occurs on the thirst center, resulting in polydipsia. ${ }^{7}$ Increased thirst has been demonstrated in several studies with SV. ${ }^{10,11}$ In addition, SV may induce changes in renal tubules. ${ }^{8}$ However, the hypothesis of increased depth of sleep as a cause does not seem to explain the daytime enuresis symptom experienced by $\mathrm{Z}$ in the present study. In any case, clinicians may wish to be vigilant about this adverse effect when treating pediatric patients with SV, as the side effect can be detrimental to treatment adherence.

\section{Acknowledgment}

This study was supported by grants from the Innovationseeking Program for Doctoral Students of Central South University (NO 2013zzts078).

\section{Disclosure}

The authors report no conflicts of interest in this work.

\section{References}

1. Kaufman J, Birmaher B, Brent D, et al. Schedule for affective disorders and schizophrenia for school-age children-present and lifetime version (K-SADS-PL): initial reliability and validity data. $J$ Am Acad Child Adolesc Psychiatry. 1997;36(7): 980-988.

2. Young RC, Biggs JT, Ziegler VE, Meyer DA. A rating scale for mania: reliability, validity and sensitivity. $B r J$ Psychiatry. 1978;133:429-435.

3. Barnes TR, Drake MJ, Paton C. Nocturnal enuresis with antipsychotic medication. Br J Psychiatry. 2012;200(1):7-9.

4. Took KJ, Buck BJ. Enuresis with combined risperidone and SSRI use. J Am Acad Child Adolesc Psychiatry. 1996;35(7):840-841.

5. Egger J, Brett EM. Effects of sodium valproate in 100 children with special reference to weight. Br Med J (Clin Res Ed). 1981;283(6291): 577-581.

6. Panayiotopoulos CP. Nocturnal enuresis associated with sodium valproate. Lancet. 1985;1(8435):980-981.

7. Choonara IA. Sodium valproate and enuresis. Lancet. 1985;1(8440): 1276 .

8. Herranz JL, Armijo JA, Arteaga R. Clinical side effects of phenobarbital, primidone, phenytoin, carbamazepine, and valproate during monotherapy in children. Epilepsia. 1988;29(6):794-804.

9. Gosavi DD, Suman A, Jain M. Sodium valproate induced increased frequency of micturition and enuresis. Indian J Pharmacol. 2013;45(1): $87-88$.

10. Herranz JL, Armijo JA, Arteaga R. Effectiveness and toxicity of phenobarbital, primidone, and sodium valproate in the prevention of febrile convulsions, controlled by plasma levels. Epilepsia. 1984;25(1):89-95.

11. Kanemura H, Sano F, Maeda Y, Sugita K, Aihara M. Valproate sodium enhances body weight gain in patients with childhood epilepsy: a pathogenic mechanisms and open-label clinical trial of behavior therapy. Seizure. 2012;21(7):496-500.
Neuropsychiatric Disease and Treatment

\section{Publish your work in this journal}

Neuropsychiatric Disease and Treatment is an international, peerreviewed journal of clinical therapeutics and pharmacology focusing on concise rapid reporting of clinical or pre-clinical studies on a range of neuropsychiatric and neurological disorders. This journal is indexed on PubMed Central, the 'PsycINFO' database and CAS.

\section{Dovepress}

The manuscript management system is completely online and includes a very quick and fair peer-review system, which is all easy to use. Visit http://www.dovepress.com/testimonials.php to read real quotes from published authors. 